Eur J Health Econ 2005 · [Suppl 1] 6:66-72 DOI 10.1007/s10198-005-0321-2

Published online: 3. November 2005

(c) Springer Medizin Verlag 2005

Ivan Planas-Miret · Ana Tur-Prats · Jaume Puig-Junoy

Department of Economics and Business, Center for Research in Health and Economics, Universitat Pompeu Fabra, Barcelona, Spain

\title{
Spanish health benefits for services of curative care
}

tice, and Defense Ministries) share these responsibilities and therefore determine the health benefit basket, although the Ministry of Health and Consumer Affairs plays the main role in finally determining any health policies.

Regional governments (ACs) have the responsibility for planning, financing, and providing health care services (including an enlargement of the basic health benefit basket), social and community care, and public health. Another important agent in coordinating and evaluating new benefits is the Institute of Health Carlos III. Local governments are responsible for homebased nursery and social services. Coordination takes place in the Inter-Territorial Council of the NHS, and advisory committee comprising representatives from the central and regional governments that is responsible for ensuring the equality of benefits among and access across regions.

The present contribution focuses on services of curative care, excluding services such as rehabilitative care and goods dispensed to outpatients. The other categories have been studied in a detailed report as part of the Health Basket Project and are presented in Tables 1 and 2, including the benefit defining criteria. We first present an overview of the basic benefits that all ACs should provide and describe the additional benefits that some ACs include in their own basket. We then discuss the benefit catalogues and their actual implementation.

\section{Definition and structure of the main benefit basket for curative care}

With regards to benefit coverage the Spanish Constitutional Act stipulates Spanish citizenship as the only precondition for access to the range of health care benefits. Parliamentary ratification on 18 December 1997 [3] extended coverage to the entire resident population. The major differences between ACs are related to foreigners.

The fundamental act on health benefit regulation is Royal Decree 63/1995 (20 January) on the organization of health services provided by the NHS (• Fig. 1 ). It provides inclusion and exclusion criteria and defines the current level of provision as the guaranteed basic health care basket in a comprehensive form. It contains a checklist of services that constitute the entitlement, establishes certain exclusion criteria, and limits the provision of certain services due to the limited resources available to the NHS. It also stipulates condi-

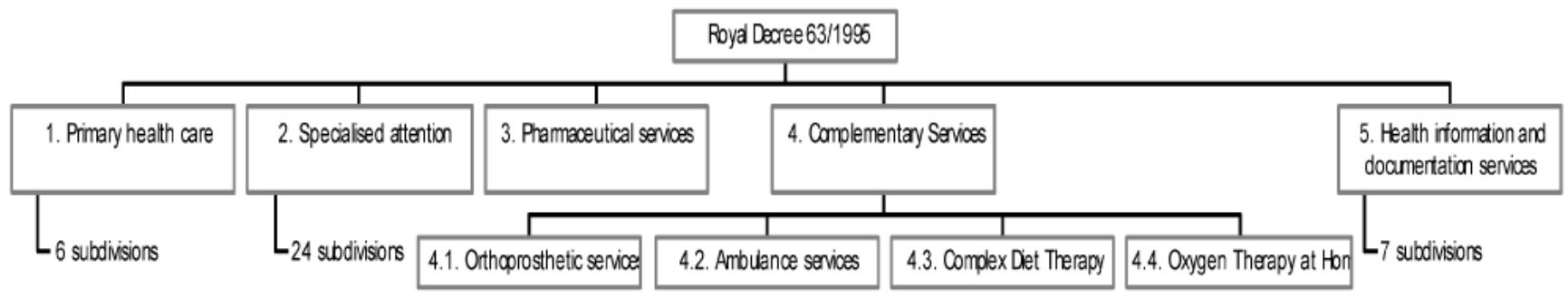

Fig. $1 \triangle$ Royal Decree 63/1995 
Table 1

Benefit-defining laws/decrees and catalogues and the implicit regulation by sector. I

$\begin{array}{llllll}\text { General Health Act } & \begin{array}{l}\text { Royal Decree } \\ 63 / 95\end{array} & \text { Law 16/03 } & \text { Ministerial } & \text { Ministerial } & \text { Ministerial } \\ & & & \text { Decree } & \text { Decree } & \text { Decree } \\ & & & \text { 30 April } 1997 & \text { 3 June 1998 } & \text { 3 March 1999 }\end{array}$

\section{Functional categories}

-HC.1.1

-HC.1.2

-HC.1.3

•HC.1.3.1

• HC.1.3.2

•HC.1.3.3

$\cdot$ HC.1.3.4

-HC.1.4

-HC.2.1

-HC.2.2

- HC. 2.3

- HC.2.4

- HC. 3

-HC.4.1

-HC.4.2

-HC.4.3

Legal status

$+$

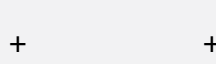

$+$

$+$

$+$

\begin{tabular}{ll} 
& \\
Decision maker & Decree \\
\hline
\end{tabular}

\begin{tabular}{lllllll} 
Decision maker & Parliament & Government & Parliament & Government & Government & Government \\
\hline Degree of explicitness & $\mathbf{1}$ & 3 & 2 & 3 & 3 & 3 \\
\hline $\begin{array}{l}\text { Positive/negative } \\
\text { definition of benefits }\end{array}$ & $\mathrm{P}$ & $\mathrm{P}$ & $\mathrm{P}$ & $\mathrm{P}$ & $\mathrm{P}$ & $\mathrm{P}$ \\
\hline $\begin{array}{l}\text { Original purpose } \\
\text { General definition of } \\
\text { entitlements }\end{array}$ & Basket & $\begin{array}{l}\text { Equality among } \\
\text { citizens and ACs }\end{array}$ & Basket & Basket & Basket \\
\hline
\end{tabular}

Criteria used for defining benefits

- Need

- Costs

- Effectiveness

- Cost-effectiveness

- Budget

Updating

+
-
-
-
-
No

+
+
+
-
-
No

$\begin{array}{lll}+ & + \\ + & + \\ + & + \\ - & - \\ \text { No } & -\end{array}$

\begin{tabular}{lll}
+ & + & + \\
+ & + & + \\
+ & + & + \\
- & - & - \\
- & - & - \\
\hline Regularly & Regularly & Regularly
\end{tabular}

a 1, all necessary; 2 , areas of care; 3 , items

tions for the introduction of new technologies and procedures as well as new entitlements. Finally, it prescribes coordination between health and social care.

Services, activities, and procedures are excluded under any of the following circumstances: (a) There is insufficient scientific evidence of their clinical safety and efficacy or if they are clearly outdated. (b) They have not sufficiently proven their effective contribution to prevention, treatment, or cure illnesses, preservation or improvement of life expectancy, self-help, or elimination or reduction of pain and suffering. (c) They are constitute merely activ- ities such as those of leisure, rest, comfort, sport, cosmetic improvement, or spa.

The Spanish NHS has not yet in fact defined a basic basket of services, although Royal Decree 63/1995 established a general framework of benefits, as did the Law $16 / 2003$ of 28 May (• Fig. 2). This law on "Cohesion and Quality of the NHS" is a reform that built on the previous act with the purpose of coordinating a strongly decentralized activity. Its aim is to establish the legal framework for the coordination and cooperation of the Public Health Administrations guaranteeing equality, quality, and participation in the system. It also introduced the establishment of a general procedure for revisions on the content of the health benefit basket. Since 2002 all ACs have health service responsibilities. They manage their regional health care system and also have related legislative responsibilities. These regional health care baskets must include at least the benefits defined by the NHS. In this sense Law 16/2003 is intended to sustain the coordination and the basic guarantees between all the territories.

Chapter I of Law 16/2003 refers to health care benefits of the NHS and defines a catalogue that incorporates the benefits defined by Royal Decree 63/1995, public health ben- 
Eur J Health Econ 2005 - [Suppl 1] 6:66-72

DOI 10.1007/s10198-005-0321-2

(C) Springer Medizin Verlag 2005

Ivan Planas-Miret · Ana Tur-Prats Jaume Puig-Junoy

\section{Spanish health benefits for services of curative care}

\begin{abstract}
This contribution presents entitlements and benefits, decision criteria, and involved actors for services of curative care in Spain. It describes basic benefits included in the category of curative care defined by the central government and any additional benefits that some autonomous communities (ACs) have included to enlarge their own basket. It is concluded that there is no specific and explicit benefit catalogue. As no user charges exist for this category, waiting times serve as the main cost containment tool. There is a need for further legislation, as inequalities may increase across the territory as a matter of fact. Inequalities in access to health care resources between $\mathrm{ACs}$ are not due to differences in health baskets but mainly to the availability of technologies.
\end{abstract}

\section{Keywords}

Health benefit plans - Health services . Health priorities - National health programs . Spain efits. The catalogue of benefits is defined as a set of preventive, diagnostic, therapeutic, rehabilitative services, and direct health promotion to citizens, which includes public health, primary and specialized care, social and community care, dietetic urgencies, pharmacy, orthoprosthesis, products, and sanitary transport benefits. It guarantees the right of all citizens to obtain a second medical opinion, the right to receive medical assistance in one's own AC of residence within a maximum time along, and the right to receive the defined benefits of the NHS under the same conditions and guarantees as residents in other ACs.

As a further development of the 16/2003 Law the Spanish Ministry of Health is currently drafting a Royal Decree to establish the NHS health benefit basket and the means for updating it. The purpose of the Royal Decree is to guarantee equality and appropriate care by the NHS. The ACs approve their own baskets by always including all the services of the NHS health benefit basket since these services are considered a basic need and common to all users of the NHS. They can enlarge their own baskets with additional technical services, technologies, and procedures. New benefits added to the basic basket are evaluated by the Ministry of Health through the Evaluation Agency of Health Technologies ("Agencia de Evaluación de Tecnologías Médicas") and the Carlos III Health Institute in collaboration with other evaluation agencies proposed by the ACs and the Inter-Territorial Council of the NHS.

\section{Contents of the benefit baskets for curative care}

\section{Inpatient curative care}

The above regulation affecting inpatient curative care defines the benefits covered by the NHS which ought to be provided by all ACs (free of any user payment) such as: specialized health care in hospitals, which includes medical attention, surgery, obstetric, and pediatric services for acute conditions, worsening of chronic conditions or delivery of recommended diagnostic treatments or procedures; organs, tissues and cells of human origin transplants according to the special legislation as long as there is the evidence for therapeutic effec- tiveness; palliative care to terminally ill patients; and mental health care and psychiatric assistance, which includes clinical diagnosis and follow-up and the prescribed group of family psychotherapy if it implies hospitalization when required. Hospitalizations of short or medium periods of time take place in the psychiatric departments of general hospitals. Inpatient mental longterm care services take place at psychiatric hospitals, which are part of the long-term care network (local authorities).

The main benefit exclusions are mental inpatient care (included only upon referral) and transplants of hair, nails, and placenta. Additional benefits on the part of ACs include sex/gender change surgery intervention, such as that now offered in Andalusia. Andalusia also offers epidural anesthetics during birth. The other main benefit extension is related to euthanasia. Catalonia, Galicia, and Extremadura have regulated and included the vital testament as a benefit.

\section{Day cases of curative care}

The entitlements concerning day cases of curative care define the service groups included in the Spanish benefits basket as: specialized ambulatory health care consultations that could include minor surgical procedures; specialized ambulatory health care delivered in "day hospitals" for patients in need of continuous specialized care, physician's or nursing services, including major surgery as long as no hospitalization is required; and hemotherapy. The following services are explicitly excluded: plastic surgery when it is not related to accident, disease, or congenital malformation; sex change surgery, except for those cases in which it is necessary to repair pathological intersexual conditions.

\section{Services of outpatient care}

Outpatient care is generally provided in primary care centers or specialist care centers (outpatient clinics). There is a wide disparity in the number and use of the latter among ACs. These categories of care are regulated both at national and AC levels. The outpatient benefit basket includes the following service groups (all free of user charges): health assistance for health consultation services and centers including basic medi- 


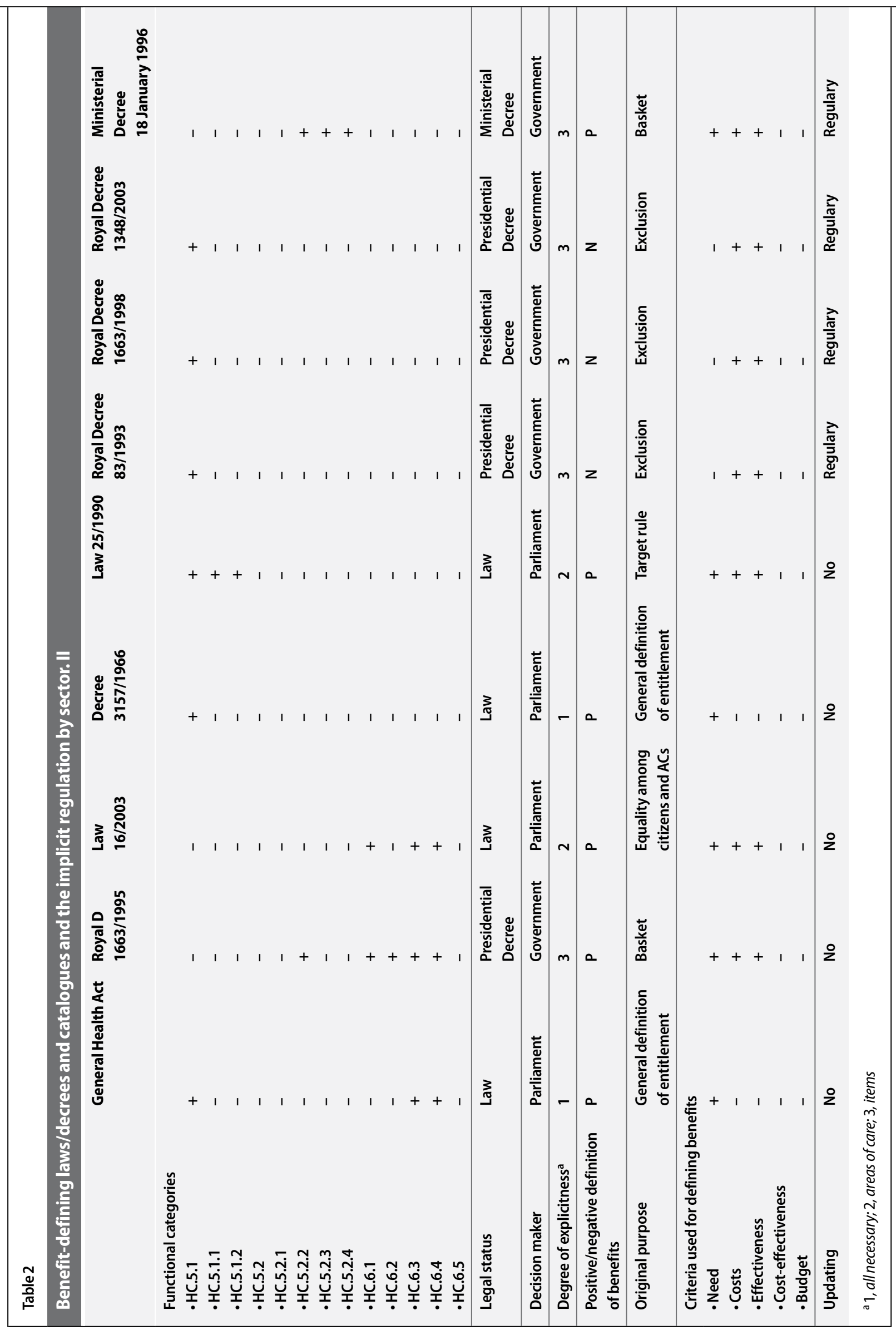




\section{Original Papers}

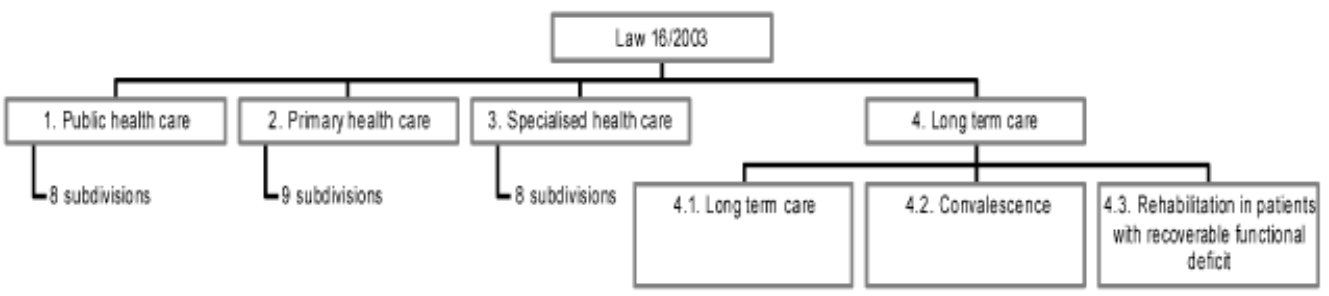

Fig. $2<$ Law 16/2003

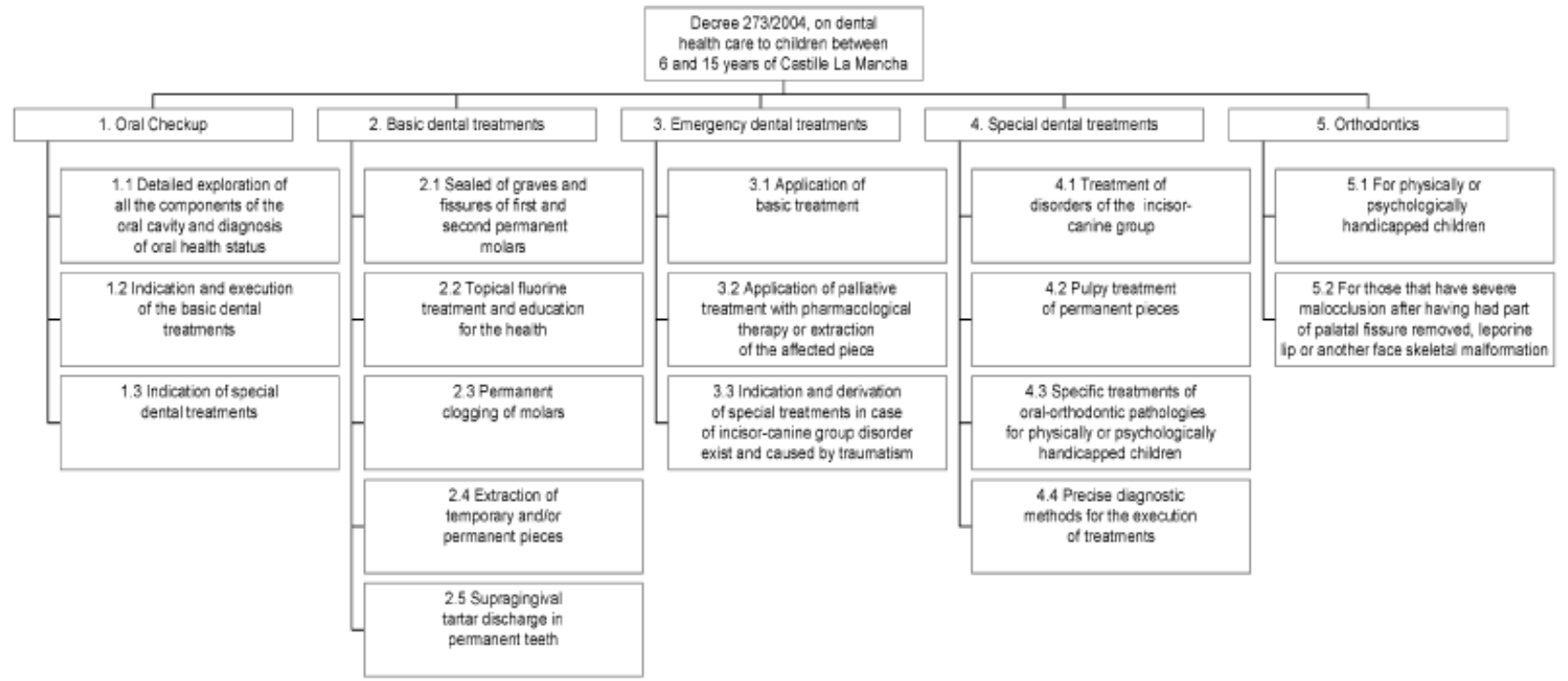

Fig. $3 \Delta$ Dental care catalogues: the example of Castilla La Mancha

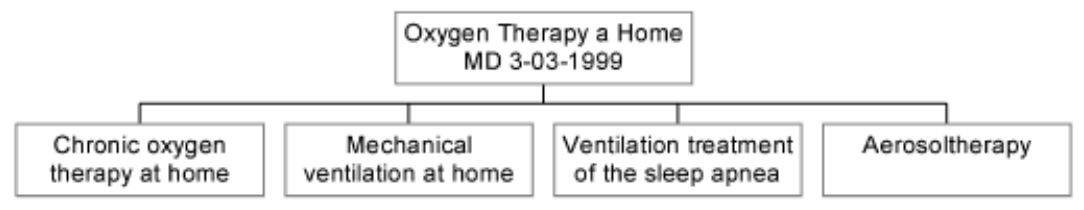

Fig. $4<$ Oxygen therapy at home

cal and diagnostic services (curative) primary care; health services provided at home; indication or prescription and the compliance, in relevant cases, with examinations and basic diagnostic measures as indicated by the primary care physician; the administration of parenteral treatments, cures and minor surgery; initial mental assistance is provided in mental health centers, where patients are being evaluated, assisted, or referred to other assistance services. Benefits provided include: pharmacological and psychotherapy treatments, crisis interventions, etc. Mental emergencies can also be treated at the hospital emergency service; emergency primary health care which will be provided to persons of any age and delivered continuously $24 \mathrm{~h}$ a day, through medical and nursing services, on an outpatient basis or at the domicile of the patient if the situation requires to do so; primary dental health care, including dental health and hygiene information and education, preventive and assistance measures; application of topical fluoride, obstructions, sealing of fissures or other services for the infant population according to the annual financial budget and special programs for dental health, treatment of acute orthodontic problems including dental extractions, and preventive exploration of the oral cavity in pregnant women; renal lithotripsy, interventionist radiology, and radiotherapy. Certain services such as complex diet therapy are not free of charge but are also not explicitly excluded from the Spanish health care benefit basket. Oth- er services such as spa treatments, rest cures, psychoanalysis, and hypnosis are explicitly excluded.

In this category of care many ACs offer additional services as part of their benefit catalogues. At primary care level the Basque Country, Extremadura, Castilla La Mancha, and Catalonia have passed several decrees; at specialized outpatient care level Navarre offers obstetrics, gynecological and family planning such as menopause care; Valencia provides reactive strips for determining glucose in blood and urine to diabetics; and at special treatment level the Balearic Islands offer neurological reflexology in cooperation with the Kovacs Foundation. It must also be noted that Catalonia has started a pilot expe- 
Table 3

Spending in the provision of health care services not included in the benefit catalogue of the National Health System (Royal Decree 63/1995): proportion of total health care services spending

\begin{tabular}{llllll} 
& 1999 & 2000 & 2001 & 2002 & 2003 \\
Total & 0.15 & 0.13 & 0.13 & 0.12 & 0.11 \\
\hline Andalusia & 0.40 & 0.32 & 0.32 & 0.30 & 0.29 \\
\hline Aragon & - & - & - & - & - \\
\hline Asturias & - & - & - & 0.0003 & 0.0007 \\
\hline Balearic Islands & - & - & - & - & 0.02 \\
\hline Canary Island & - & - & - & - & - \\
\hline Cantabria & - & - & - & - & - \\
\hline Castilla y León & - & - & - & - & - \\
\hline Castilla-La Mancha & - & - & - & - & - \\
\hline Catalonia & 0.40 & 0.38 & 0.36 & 0.32 & 0.27 \\
\hline Valencia & - & - & - & - & - \\
\hline Extremadura & - & - & - & - & 0.04 \\
\hline Galicia & - & - & - & - & - \\
\hline Madrid & - & - & - & - & - \\
\hline Murcia & - & - & - & - & 0.05 \\
\hline Navarre & 0.47 & 0.44 & 0.47 & 0.46 & 0.49 \\
\hline Basque Country & 0.20 & 0.18 & 0.19 & 0.18 & 0.19 \\
\hline La Rioja & - & - & - & - & - \\
\hline Ceuta & - & - & - & - & - \\
\hline Melilla & - & - & - & - & - \\
\hline
\end{tabular}

rience in offering acupuncture for arthritis treatment.

Nine ACs also provide free dental care for some groups: Navarre, Basque Country, Andalusia, Extremadura, Castilla La Mancha, Cantabria, Castilla León, Murcia, and Galicia. Catalonia offers periodic rinsing of a fluorine solutions program for primary school students and those taking the first two courses of secondary school. As all these catalogues are quite similar, we present below the dental care benefit catalogue of Castilla La Mancha (• Fig. 3). The InfantYoung Dental Care Plan defines the group of measures and activities, both preventive and welfare, as well as any procedures to provide dental care. Benefits are classified into: oral check-up, basic dental treatments, emergency dental treatments, special dental treatments, and orthodontics.

\section{Services of curative home care}

As part of the entitlements of services of curative home care, oxygen therapy service at home is provided at authorized and specialized centers capable of carrying out gasometry and spirometry. The Ministerial Decree of 3 March 1999 [4] elaborates these services, considering the following benefits: (a) oxygen therapy at home, (b) mechanical ventilation at home, (c) ventilation treatment of the sleep apnea symptoms, and (d) aerosol therapy. Enteral nutrition is also provided at home. This service is made available to patients who suffer from the following symptoms: swallowing, transit, digestion or absorption of foods in its natural form problems or when special requirements of energy and/ or nutrients exist that cannot be covered with foods of daily consumption.

Royal Decree 63/1995 has been developed with regard to benefits with diet products in two ways: regulating complex diet therapy and regulating enteral nutrition at home. Complex diet therapy is dealt with in the Ministerial Decree of 30 April 1997 [5] which specifies the relationship of congenital metabolic upheavals of carbon hydrates and amino acids included in this benefit and the type of diet in each case. It also prescribes these treatments to be performed by a special physician in hospital units, specifically authorized by the appropriate Health Administration. Enteral nutrition at home is regulated by the Ministerial Decree of 2 June 1998 [6], which defines the requirements and the patient's clinical situation for this. There are also regulations at the national and interterritorial council levels as well as in six ACs that have developed their own dietetic regulations.

The Ministerial Decree of 3 March 1999 was passed upon the proposal of a panel of experts (• Fig. 4). This elaborates Royal Decree 63/1995 regarding the techniques of oxygen therapy at home financed by the NHS and clarifies and standardizes the criteria, clinical situations, and other matters for the direction, prescription, and provision of these benefits. It defines the oxygen therapy techniques that can be carried out at home in terms of their financing by the NHS and establishes the basic requirements that justify their prescription. The Ministerial Decree of 3 March 1999 thus provides a common basis upon which the health service providers must develop their own procedure for providing and supervising these benefits. The Decree actually does not provide a benefit catalogue as such because the individual physician determines the specific treatment in each case. In addition there are also specific regional oxygen therapy regulations in four ACs (Andalusia, Canary Islands, Navarre and Valencia).

\section{Services of MUFACE catalogue}

All civil servants and beneficiaries are entitled to receive benefits as determined by the MUFACE catalogue. This benefit basket is virtually equivalent to that of the NHS but include some additional benefits. The principal difference is related to copayments for pharmaceuticals. In addition to particular features for medical assistance abroad, orthoprosthetic, dental care, ocular, pharmaceutical, and sociosanitary benefits, services such as vaccinations are included free of charge. Specialized health care includes all the medical and surgical specialties, both in outpatient and inpatient sectors. The specialties are structured in four levels according to their complexity and geographic scope, sanitary transport, oxygen therapy, and aerosol therapy at home. 


\section{Discussion}

The way in which the Spanish benefit catalogue is defined is characteristic of taxfinanced NHS health care systems. A system such as that in Spain which guarantees universal coverage is not completely developed until it is specifies a minimum basket of health care services. However, as no specific and explicit benefit catalogue is being developed, there remains a need for further legislation. The Ministry of Health and Consumption is moving towards an explicit process of decision making in health benefit planning instead of defining a detailed benefit catalogue.

As is the case in many countries, the possibility of using regional plans as the basis for resource allocation and capacity planning has not yet been considered. An additional problem in Spain is the fact that the majority of health care plans offer unrealistically long lists of objectives which are often not sufficiently based on available epidemiological and cost-effectiveness evidence, and their efficacy is seldom evaluated. They cannot be considered as benefit catalogues since they are not sufficiently strong legal instruments, and therefore users are not able to claim the objectives contained in the health plans as benefit rights.

Then purpose of the Spanish health benefits basket is twofold, as it was initially established to serve more as a budgetary than as a cost containment measure when created by the Social Security act [7]. However, on the other hand, as Royal Decree 63/1995 and the 2003 Cohesion Law recognize, they are merely an ordering of benefits as they try only to describe what is being offered in practice.

Two major aspects of the Spanish health care system are: (a) A more explicit definition of the benefit basket is needed as the present vague definition leaves the final decisions to practitioners, making expenditure very volatile, and having as the sole restriction that of waiting times. (b) Greater transparency is needed in the process of approval/rejection of new benefits, towards agents in the health sector, and towards citizenship along with the need to include economic considerations in the decision process. In Spain it still remains the case: "all for everyone and almost everything for free." This obviously leads to long waiting times and thus a dual system (public-private) for those able to skip the long queues and high public pressure over resources devoted to the NHS. Furthermore, since there are no user payments, waiting lists serve as the mechanisms restricting demand for health services. For the first time, the Catalan Health Service is now studying the possibility of introducing a copayment system in primary care (fixed payment per visit).

There are still some remaining problems in the Spanish benefit basket. In terms of equality, the fact that MUFACE-type schemes have not been fully integrated to the NHS provides additional benefits for these groups. There is a lack of real control over the managers of the health care services. Autonomy of decisions by practitioners may mean an obstacle to the early evaluation of new technologies since under uso tutelado (monitored use) it is physicians who start using them. In the present financing system there is no relationship between this and the benefits provided, nor a control mechanism over what is provided in reality.

Moreover, the information systems are clearly the main problem in the decentralization process. To overcome this problem the Ministry of Health has recently introduced an institution for monitoring the health system. Even the appearance of new benefit differences across ACs will not affect equality such as it may affect clinical practices and access to equipment. Therefore the main purposes of the Spanish health policy are to promote common clinical guidelines and evaluation processes with a single registry on new infrastructure and the creation and regulation of a common procedure for new benefit approvals.

In the future the central government is not expected to increase benefits but rather the quality of the existing ones, through new technologies and clinical procedures. Improvements are expected regarding the provision of services (e.g., waiting times), better user information, and increased range of choices. Probably the most important task is the development of a long-term care or dependency system and a real network of mental health.

Future reforms taken by the different ACs will likely address the benefits basket. Dental care and natural and alternative medicines are probably the first services that will be addressed. The definition of a basic long-term social and community care benefit basket similar to that in health care will also be a priority for the central government. Nevertheless, as we can see in - Table 3, new benefits have very little impact on the health expenditure of ACs.

Finally, in Spain, the growth of public health expenditure is due to both the increase in input prices and the received average benefits per capita. The growth of public health care expenditure is largely attributable to the benefits provided. The yearly change in health care benefits was responsible for $1.86 \%$ of the $6.73 \%$ annual average increase in health expenditure between 1991 and 2003.

\section{Corresponding author Jaume Puig-Junoy}

Center for Research in Health and Economics, Universitat Pompeu Fabra, Barcelona, Spain e-mail: jaume.puig@upf.edu

\section{Acknowledgements}

The results presented here are based on the project"Health Benefits and Service Costs in EuropeHealthBASKET" which is funded by the European Commission within the Sixth Framework Research Programme (grant no. SP21-CT-2004-501588).

\section{References}

1. (Anonymous) (2003) Ley $16 / 2003$, de 28 de mayo, de Cohesión y Calidad del Sistema Nacional de Salud. Boletín Oficial del Estado 128. http://www.boe.es/boe/dias/2003-05-29/pdfs/A20567-20588.pdf

2. (1995) Real Decreto 63/1995, de 20 De Enero, sobre Ordenacion de Prestaciones Sanitarias del Sistema Nacional de Salud. Boletín Oficial del Estado 35. http://www.boe. es/g/es/boe/dias/1995-02-10/seccion1.php?p=p

3. Congreso de los Diputados, Pleno (1998) Creación de una Subcomisión para avanzar en la consolidación del Sistema Nacional de Salud mediante el estudio de las medidas necesarias para garantizar un marco financiero estable y modernizar el Sistema Sanitario manteniendo los principios de universalidad y equidad en el acceso. BOCG 230. http://www.congreso.es/public_oficiales/L6/CONG/BOCG/D/D_230.PDF\#page=1

4. Ministerio Sanidad y Consumo (1999) Regulación de las técnicas de terapia respiratoria a domicilio en el Sistema Nacional de Salud. Boletín Oficial del Estado 62:10252. http://www.boe.es

5. Ministerio Sanidad y Consumo (1997) Asistencia sanitaria de la Seguridad Social. Regula los tratamientos dietoterápicos comple5jos. Boletín Oficial del Estado 115:15047. http://www.boe.es

6. Ministerio Sanidad y Consumo (1998) Asistencia sanitaria de la Seguridad Social. Regula la nutrición entera domiciliaria en el Sistema Nacional de la Salud. Boletín Oficial del Estado 139:19294. http://www.boe.es

7. Jefatura del Estado (1963) RCL 1963 2467/Ley 193/1963, de 28 diciembre. Seguros Sociales. Bases de la Seguridad Social. Boletín Oficial del Estado 312:18181 rect. 24:1182 (1964). http://www.boe.es 